\title{
Correction to: Non-surgical Risk Factors for the Development of Chylothorax in Children after Cardiac Surgery-Does Fluid Matter?
}

\author{
Tanya Perry ${ }^{1}$ (I) $\cdot$ Kelly Bora ${ }^{2} \cdot$ Adnan Bakar ${ }^{2,3} \cdot$ David B. Meyer $^{4} \cdot$ Todd Sweberg $^{2}$
}

Published online: 3 December 2019

○) Springer Science+Business Media, LLC, part of Springer Nature 2019

\section{Correction to: Pediatric Cardiology} https://doi.org/10.1007/s00246-019-02255-4

The article Non-surgical Risk Factors for the Development of Chylothorax in Children after Cardiac Surgery-Does Fluid Matter?, written by Tanya Perry, Kelly Bora, Adnan Bakar, David B. Meyer and Todd Sweberg, was originally published electronically on the publisher's internet portal (currently SpringerLink) on November 2019 with open access.
With the author(s)' decision to step back from Open Choice, the copyright of the article changed on November 2019 to $\odot$ Springer Science+Business Media, LLC, part of Springer Nature 2019 and the article is forthwith distributed under the terms of copyright.

Publisher's Note Springer Nature remains neutral with regard to jurisdictional claims in published maps and institutional affiliations.

The original article can be found online at https://doi.org/10.1007/ s00246-019-02255-4.

Tanya Perry

Tanya.Perry@cchmc.org

1 Division of Cardiology, Department of Pediatrics, The Heart Institute, Cincinnati Children's Hospital Medical Center, 3333 Burnet Ave, Cincinnati, OH 45229, USA

2 Division of Pediatric Critical Care, Department of Pediatrics, Steven and Alexandra Cohen Children's Medical Center, New Hyde Park, NY, USA

3 Division of Cardiology, Department of Pediatrics, Steven and Alexandra Cohen Children's Medical Center, New Hyde Park, NY, USA

4 Division of Cardiothoracic Surgery, Department of Pediatrics, Steven and Alexandra Cohen Children's Medical Center, New Hyde Park, NY, USA 